\title{
Th17 Transcription Factor RORC2 Is Inversely Correlated with FOXP3 Expression in the Joints of Children with Juvenile Idiopathic Arthritis
}

\author{
BIAGIO OLIVITO, GABRIELE SIMONINI, SARA CIULLINI, MARIA MORIONDO, LETIZIA BETTI, \\ ELEONORA GAMBINERI, LUCA CANTARINI, MAURIZIO DE MARTINO, CHIARA AZZARI, \\ and ROLANDO CIMAZ
}

ABSTRACT. Objective. To investigate the relationship between interleukin 17 (IL-17) producing T cells (Th17) and CD4+CD25+FOXP3+ regulatory T cells (Tregs) in blood and synovial fluid (SF) of patients with juvenile idiopathic arthritis (JIA).

Methods. Sixty-five children with JIA (18 males and 47 females, median age 6.2 yrs; 45 with oligoarticular and 20 with polyarticular course) and 75 age- and sex-matched healthy controls were studied. Flow cytometry was used to analyze the forkhead box P3 (FOXP3)-positive Treg cells in peripheral blood (PB) and synovial fluid mononuclear cells (SFMC). FOXP3 and retinoic-acid related orphan receptor $\mathrm{C}$ isoform 2 (RORC2) messenger RNA (mRNA) were assessed by real-time polymerase chain reaction analysis. Cytokines (IL-17 and Th1/Th2 related cytokines) were measured in culture supernatants of 11 paired PBMC and SFMC activated with PMA and ionomycin.

Results. FOXP3+ T cells and FOXP3 mRNA amounts were significantly lower in PB of children with JIA as compared with controls ( $p=0.0002$ and $p=0.001$, respectively) and a higher percentage of Treg cells with concomitant higher level of FOXP3 transcript levels were observed in SF when compared with their PB counterparts (both $\mathrm{p}<0.0001$ ). SF CD4+FOXP3+ T cells were characterized by higher amounts of FOXP3 protein per cell when compared with peripheral CD4+FOXP3+ T cells, as revealed by the difference in FOXP3 median fluorescence intensity (median \pm SD, arbitrary units, $54 \pm 22.6$ vs $19.5 \pm 4.2 ; \mathrm{p}<0.001)$. RORC2 transcript levels were higher in JIA joints when compared with matched PB samples (median fold increase 3.9, p < 0.0001) but negatively correlated with FOXP3 mRNA levels $(r=-0.623, p=0.04)$. Stimulated SFMC displayed an impaired ability to produce IL-17 when compared with PBMC and, interestingly, an inverse relationship between IL-17 levels and the percentage of CD4+CD25+FOXP3+ SF T cells $(r=-0.510$, $p$ $=0.047$ ) was seen.

Conclusion. We demonstrated for the first time an increased synovial expression of the transcription factor of Th17, RORC2, in JIA, and its inverse relationship with FOXP3 mRNA. These results extend research on "Th17" and Tregs in JIA. (First Release Aug 1 2009; J Rheumatol 2009; 36:2017-24; doi:10.3899/jrheum.090066)

Key Indexing Terms:

$\begin{array}{llll}\text { JUVENILE IDIOPATHIC ARTHRITIS } & \text { FOXP3 } & \text { INTERLEUKIN } 17 & \text { Th17 }\end{array}$

RETINOIC ACID RELATED ORPHAN RECEPTOR C

From the Department of Paediatrics, Anna Meyer Children's Hospital and University of Florence, Florence; and Department of Clinical Medicine and Immunologic Sciences, Le Scotte University Hospital, University of Siena, Siena, Italy.

Funded in part by the French parents' association "Kourir."

B. Olivito, BSc; G. Simonini, MD; S. Ciullini, BSc; M. Moriondo, BSc;

L. Betti, BSc; E. Gambineri, MD, Department of Paediatrics, Anna Meyer Children's Hospital and University of Florence; L. Cantarini, MD,

Department of Clinical Medicine and Immunologic Sciences, Le Scotte University Hospital, University of Siena; M. de Martino, MD, C. Azzari, MD, PhD; R. Cimaz, MD, Department of Paediatrics, Anna Meyer Children's Hospital and University of Florence.

Address correspondence to B. Olivito, Department of Paediatrics, Rheumatology and Immunology Unit, University of Florence, Anna Meyer Children's Hospital, Viale Pieraccini 24, 50139, Florence, Italy.

E-mail:b.olivito@meyer.it

Accepted for publication April 24, 2009.
Juvenile idiopathic arthritis (JIA) is a clinically heterogeneous group of childhood arthropathies of unknown cause, which is characterized by the accumulation of T lymphocytes at the site of inflammation ${ }^{1}$. Until now, a chronic Th1-polarized immune response has been thought to play an important role in the development of many organ-specific autoimmune diseases ${ }^{2}$, including rheumatoid arthritis (RA) and JIA ${ }^{3,4}$. The recent discovery of new lineages of CD4+ T cells, distinct from Th1 and Th2, such as the interleukin 17 (IL-17) producing $\mathrm{T}$ cells (now widely known as Th17 cells) ${ }^{5,6}$, and regulatory $\mathrm{T}$ cells (Tregs) ${ }^{7}$ provides new frameworks for understanding $\mathrm{T}$ cell biology in human autoimmune diseases, indicating that the Th1/Th2 dichotomy represents only part of a heterogeneous view of a com- 
plex and partially understood $\mathrm{T}$ cell response pattern ${ }^{8-10}$. Th17 and Treg cells modulate immune responses in antagonistic fashion and an imbalance of their activity and of their products seems to contribute to the immune dysregulation associated with several autoimmune disease ${ }^{11}$. For example, it has been documented that Th17 cells and their effector cytokines mediate host defense mechanisms to various infections and are involved in the pathogenesis of many autoimmune diseases ${ }^{12,13}$.

IL-17 plays a major role in RA, mediating various aspects of the joint damage ${ }^{14}$ and promoting expression of diverse proinflammatory cytokines ${ }^{15}$. Over-expression of IL-17 in the joints also exacerbates experimental arthritis ${ }^{16,17}$, and a reduction in joint inflammation was reported in IL-17A-deficient mice following type II collagen immunization ${ }^{18}$. In agreement with these findings, IL-17 is detected in increased quantities in RA synovial fluid (SF) ${ }^{19-21}$ and, more recently, has been found at high levels also in JIA $\mathrm{SF}^{22}$. Overall, these data support the involvement of IL-17 in arthritis development and suggest it may play an important role directly or through induction of other proinflammatory and destructive mediators, presumably via the interaction with Th1/Th2 polarized cells and their effector cytokines.

In contrast to Th17 cells, Tregs are now widely regarded as the primary mediators of peripheral tolerance ${ }^{23,24}$, modulating self-reactive immune responses through various potential suppression mechanisms, which could reflect the functional heterogeneity among Treg cell subsets ${ }^{25}$. To date, only those cells expressing forkhead box P3 (FOXP3+) have been extensively studied. Among these populations, which appear predominantly in CD4+ cells, 2 prominent subtypes have been characterized: naturally occurring, thymusderived CD4+ cells that express CD25, the $\alpha$ chain of the interleukin 2 (IL-2) receptor (nTregs) ${ }^{26}$, and adaptive CD4+CD25+ cells that are induced from CD25- precursors in peripheral lymphoid organs (iTregs) ${ }^{27,28}$. Interestingly, like the Th1/Th2 T cell subset, also Th17 and Treg cells not only exhibit different functional properties, but also show preferential expression of distinct transcription factors: retinoic acid-related orphan receptor gamma $t(R O R \gamma t)$ for Th17 cells ${ }^{29}$ and FOXP3 for Treg cells ${ }^{30,31}$. ROR $\gamma$ t is a nuclear receptor, encoded within the RORC locus, initially identified for its ability to down-regulate Fas ligand expression and IL-2 production, protecting $\mathrm{T}$ cells from activationinduced apoptosis ${ }^{32}$.

In humans, 2 transcript variants encoding isoforms of different sizes have been found for the RORC gene: RORC1 (RORC transcript variant 1, the longer transcript that appears to be expressed broadly) and RORC2 (RORC2: a short isoform that is expressed exclusively in cells of the immune system and shares with RORC1 identical nucleotide sequences from exon 3 through the last exon) $)^{32}$. ROR $\gamma t$ and its human ortholog RORC2 are known to require differentiation of mouse and human Th17 cells, respective$\left.1 y^{29,33}\right)$. Recently, a reciprocal developmental pathway for the generation of pathogenic Th17 cells and protective Treg cells has been reported ${ }^{34}$. Interestingly, differentiation of both cell types requires transforming growth factor- $\beta$ (TGF- $\beta$ ), but the presence of IL-6 inhibits Treg development while converting naïve $\mathrm{T}$ cells into Th17 cells, suggesting that the function of TGF- $\beta$ may be dependent on the local inflammatory context ${ }^{35-37}$.

Recently, Th17 cells were found to be highly enriched in JIA synovium, and a reciprocal relationship between Th17 and Treg cells was also demonstrated ${ }^{38}$. Given these findings, we further investigated Treg cells in JIA, paying particular attention to the molecular aspect of the Th17-Treg network in this disease. In particular, we sought to evaluate the percentage of FOXP3-expressing CD4+ T cells in JIA patients and controls, determine the density/cell of FOXP3, and study FOXP3 and RORC2 transcript levels in peripheral blood (PB) and SF mononuclear cells.

\section{MATERIALS AND METHODS}

Patients. All subjects (patients and controls) were prospectively recruited from the Pediatric Rheumatology Unit of Anna Meyer Children's Hospital in Florence, Italy, from June 2007 to June 2008. Sixty-five children with JIA (47 females, 18 males, median age 6.2 years; range 2.8-15.4) and 75 age and sex-matched healthy controls without inflammatory conditions were enrolled. All JIA patients fulfilled the revised criteria of International League of Associations for Rheumatology criteria for JIA ${ }^{39}$ and had the following disease course: 45 oligoarticular and 20 polyarticular. Patients were also subdivided into active $(n=44)$ and inactive $(n=21)$ JIA groups according to the presence or absence of active arthritis at the time of sampling. No patient had systemic onset disease.

At the time of enrollment, 13 JIA children were off therapy, 24 were taking nonsteroidal antiinflammatory drugs (NSAID) only; 4 were taking methotrexate; 12 were taking methotrexate in addition to NSAID; 6 were taking etanercept; 1 took etanercept in addition to NSAID; 2 were taking sulfasalazine; 2 took sulfasalazine in addition to NSAID; and one was taking methotrexate, etanercept, and NSAID.

In all cases blood $(5-6 \mathrm{cc})$ was collected during routine venipuncture and immediately processed. SF and PB paired samples were obtained from 20 JIA patients at the time of clinically indicated arthrocentesis for steroid injection.

Our study was approved by the Research Ethics Committee of the Anna Meyer Children's Hospital, Florence, Italy, and informed consent was obtained from parents or guardians.

Phenotypic analysis. PB mononuclear cells (PBMC) and SF mononuclear cells (SFMC) were isolated with lymphocyte separation medium (Eurobio, Ueis, France) by standard density gradient centrifugation. All phenotype analyses were performed within 3 to 4 hours of clinical sample collection. For cell surface immunostaining, PBMC and SFMC $\left(0.5-1 \times 10^{6}\right.$ cells $/ 100$ $\mu 1)$ were incubated for $15 \mathrm{~min}$ with CD4- peridinin chlorophyll protein-cyanin 5.5 and CD25 phycoerythrin-conjugated antibodies (both from BD Biosciences, San Jose, CA, USA). After cell surface staining was completed, FOXP3 intracellular staining was performed with anti-human FOXP3 flow kit (Biolegend, San Diego, CA, USA) according to manufacturer's protocol. Briefly, surface stained cells were first fixed and permeabilized with FOXP3 $1 \times$ fix/perm buffer. After washing, permeabilized cells were stained with fluorescein isothiocyanate-conjugated anti-human FOXP3 monoclonal antibody (clone 259D) or mouse IgG1 isotype control for $30 \mathrm{~min}$ in the dark. 
Cells were acquired on a FACSCanto flow cytometer and analyzed using FACSDiva software v 5.0.2 (BD Biosciences) and FlowJo software v 7.1.2 (Tree Star, Inc.).

Gates for CD4+FOXP3+ T cells were set according to isotype negative control. The gate for whole CD4+CD25+ T cells was set with their respective unstained cells (PBMC or SFMC). CD4+CD25+ T cells were classified into CD25low and CD25bright $\mathrm{T}$ cells according to published criteria $^{40}$. Median fluorescence intensity was calculated using FlowJo software and FACSDiva software, and median fluorescence intensity (MFI) values were expressed in arbitrary units (AU). For data analysis, 100,000 events were acquired for each sample and an initial lymphocyte gate was defined according to forward scatter (FSC) and side scatter (SSC).

Real-time RT-PCR. Total RNA was extracted from PBMC and SFMC using TRIzol reagent (Invitrogen, Carlsberg, CA, USA) according to the manufacturer's instructions and stored at $-80^{\circ} \mathrm{C}$ until use. The first strand of cDNA was synthesized using oligo(dT)12-18 primers and Superscript II Reverse Transcriptase (both from Invitrogen, Life Technologies). Quantitative real-time polymerase chain reaction (PCR) was performed with an ABI PRISM 7500 Sequence Detection System (Applied Biosystems) and the TaqMan Universal Master Mix reagent (Applied Biosystem, Branchburg, NJ, USA), in accordance with the manufacturer's protocol. Each sample was assayed in duplicate or triplicate for the target gene together with housekeeping gene RNase P (Taqman Rnase P control reagents, Applied Biosystem, Foster City, CA, USA) as internal reference in $25 \mu \mathrm{l}$ final reaction volume. PCR conditions were: $95^{\circ} \mathrm{C}$ for $10 \mathrm{~min}$, followed by 45 cycles of 2-stage temperature profile of $95^{\circ} \mathrm{C}$ for $15 \mathrm{~s}$ and $60^{\circ} \mathrm{C}$ for $1 \mathrm{~min}$. FOXP3 and interleukin 2-receptor $\alpha$ (IL-2R $\alpha$ ) primers and TaqMan probes were purchased as an Assay-On-Demand from Applied Biosystems (assay identification numbers: Hs 00203958_m1 and Hs 00907778m_1, respectively). RORC2 specific primers (forward primer: 5'-GAA GGA CAG GGA GCC AAG GC-3'; reverse primer: 5'-CTT GTC CCC ACA GAT TTT GCA-3' and TaqMan probe 5'-6FAM-TCA GTC ATG AGA ACA CAA ATT GAA GTG ATC CC-3'-TAM) were designed using the ABI PrimerExpress 3.0 software on the basis of available GenBank sequence (RORC Gene ID 6097; Target NM_001001523.1) and were analyzed by using Basic Local Alignment Search Tool (BLAST) service to confirm their specificity. RORC2 specific probe was designed to span exon 1-exon 2 junction in order to avoid the influence of DNA contamination. The threshold cycle number $(\mathrm{Ct})$ was determined for all PCR reactions and in most cases the threshold was manually adjusted to lie within the exponential phase using ABI 7500 Fast System SDS software.

Levels of mRNA expression for each gene were calculated using $2-\Delta \Delta C T$ method ${ }^{41}$ and the values expressed as relative arbitrary units.

Cell cultures and stimulation. PBMC and SFMC $\left(5 \times 10^{5} /\right.$ well $)$ were resuspended in RPMI 1640 supplemented with $10 \%$ heat-inactivated fetal bovine serum (HyClone Laboratories, Waltham, MA, USA), $100 \mathrm{U} / \mathrm{ml}$ penicillin and $100 \mu \mathrm{g} / \mathrm{ml}$ streptomycin (Gibco BRL), $2 \mathrm{mM}$ L-glutamine. Stimulation of PBMC and SFMC was obtained with $20 \mathrm{ng} / \mathrm{ml}$ of phorbol myristate acetate (PMA), a protein kinase C (PKC) activator, and $1 \mu \mathrm{g} / \mathrm{ml}$ of ionomycin, a calcium ionophore (both from Sigma-Aldrich, Milan, Italy). In order to test the most suitable type of stimulus for inducing IL-17 production in our culture conditions, 3 classical stimuli were also included at the indicated concentrations: Dynabeads CD3/CD28 T cell expander (Invitrogen) performed at a bead-to-cell ratio of 1:1; phytohemagglutinin 1 $\mu \mathrm{g} / \mathrm{ml}$ (Sigma-Aldrich), and plate-bound anti-CD3 $\left(1 \mu \mathrm{g} \mathrm{ml}^{-1}\right)$ plus soluble CD28 antibody ( $1 \mu \mathrm{g} \mathrm{ml}^{-1}$ ) (both from BD Biosciences, Pharmingen, San Jose, CA, USA).

Cells were cultured in 96-well U-bottom plates for $48 \mathrm{~h}$. Control (unstimulated) cells were included in each experiment. After incubation in a humidified atmosphere $\left(37^{\circ} \mathrm{C}\right.$ with $\left.5 \% \mathrm{CO}_{2}\right)$ supernatants were collected and stored at $-80^{\circ} \mathrm{C}$ until analysis of cytokine concentrations.

Cytokine assays. IL-17 production in paired PBMC and SFMC supernatants $(\mathrm{n}=11)$ was analyzed by a commercial sandwich ELISA kit (Quantikine, R\&D Systems, Minneapolis, MN, USA). IL-2, IL-4, IL-6,
IL-10, interferon- $\gamma$, tumor necrosis factor- $\alpha$ were measured simultaneously using Flex Set Cytometric Bead Array (BD Biosciences, San Diego, CA, USA) and analyzed with FCAP Array software (Becton Dickinson) according to the manufacturer's manual. Briefly, $50 \mu 1$ of mixed cytokine capture beads were added to $50 \mu 1$ of each sample or cytokine standard in flow cytometry tubes and incubated for $1 \mathrm{~h}$ at room temperature in the dark. After incubation, $50 \mu 1$ of phycoerythrin detection reagent was added, and each tube was incubated at room temperature for $2 \mathrm{~h}$ in the dark. Beads were finally washed by the addition of $1 \mathrm{ml}$ of wash buffer, pelleted by centrifugation $(180 \times \mathrm{g}$ for $5 \mathrm{~min}$ ) and resuspended with $300 \mu \mathrm{l}$ of wash buffer prior to FACSCanto analysis. Standard curves for the 6 cytokines were generated and an $\mathrm{R}^{2}>0.99$ was obtained for each cytokine, indicating that the assay was highly reproducible. The minimum detectable dose of each cytokine was evaluated according to manufacturer's instructions.

Statistical analysis. All results are expressed as mean or median \pm SD Mann-Whitney U test, Wilcoxon signed rank test for paired samples and Fisher's exact test, when appropriate, were used to compare data. Pearson and Spearman correlation tests were used to determine correlation coefficients for different variables. Non-parametric tests were used, where necessary, due to the small size of our groups and to the skewness of our data. Levels of $\mathrm{p}<0.05$ were considered statistically significant. All analyses were performed on SPSS package for Windows, version 13.0 (SPSS Inc., Chicago, IL, USA).

\section{RESULTS}

Phenotypic analysis. Flow cytometric analysis of FOXP3 expression by intracellular staining showed a significantly $(\mathrm{p}=0.0002)$ lower percentage of CD4+CD25+FOXP3+ T cells in PB of JIA patients versus controls (median $\pm \mathrm{SD}, 7.5$ +2.0 versus $5.4+2.6$, Figure $1 \mathrm{~A})$. No statistically significant difference was found between each JIA group studied (polyarticular vs oligoarticular, active vs inactive). In contrast, the percentage of CD4+CD25+FOXP3+ T cells was significantly higher in joints when compared to their PB counterparts (median $\pm \mathrm{SD}, 15.6 \pm 5.7$ vs $5.2 \pm 2.5$; p < 0.0001 , Figure 1B). No relationship was found between percentage of $\mathrm{CD} 4+\mathrm{CD} 25+\mathrm{FOXP} 3+$ (or CD4+FOXP3+) $\mathrm{T}$ cells in $\mathrm{PB}$ or $\mathrm{SF}$ and sex, age, and treatment regimen. No difference was observed in the percentage of CD4+CD25+ $\mathrm{T}$ cells in peripheral blood of patients versus healthy controls (median $\pm \mathrm{SD}, 15.4 \pm 9.3 \%$ vs $16.2 \pm 7.9 \%$ ).

In contrast to $\mathrm{PB}$, JIA patient $\mathrm{SF}$ contained a higher percentage of $\mathrm{CD} 4+\mathrm{CD} 25+\mathrm{T}$ cells (median $\pm \mathrm{SD}, 33.6 \pm$ $14.8 \%$ vs $15.4 \pm 9.3 \% ; \mathrm{p}=0.001)$ that displayed a brighter CD25 protein expression, as revealed by CD25 MFI (median MFI fold change: $1.8 \pm 0.3$, data not shown) and a higher amount of IL- $2 \mathrm{R} \alpha$ mRNA levels, as quantified by real-time PCR (median fold change: $5.1 \pm 2.1$, data not shown). When we subdivided CD4+CD25+ $\mathrm{T}$ cells into CD25low and CD25bright (see Figure 1C for gates used) we observed that the increase in percentage of SF CD4+CD25+ $\mathrm{T}$ cells was essentially due to CD4+CD25bright $\mathrm{T}$ cells, a subset characterized by the higher FOXP3 protein expression, as shown in Figure 1D. In fact, the CD25low $T$ cells had a 1.5-fold increase in SF when compared with PB (CD25low median, $19.6 \pm 12.7$ vs $13.1 \pm 6.4 ; \mathrm{p}=0.0016)$, while CD25bright had a 5.6-fold increase (10 \pm 4.5 vs $1.8 \pm$ 

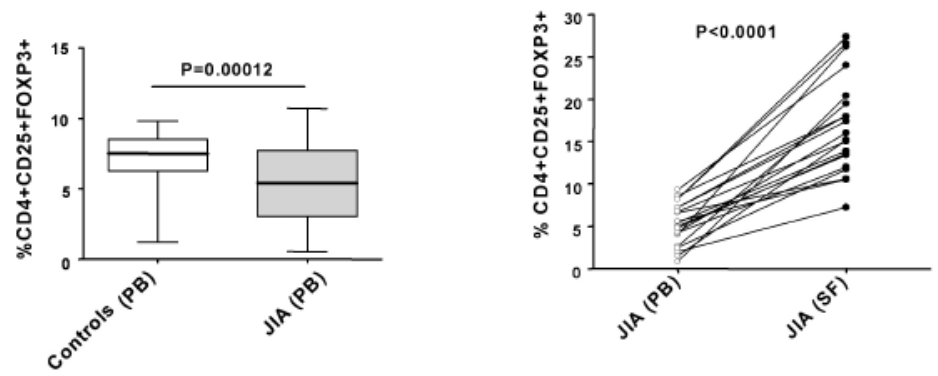

C

PB

SF

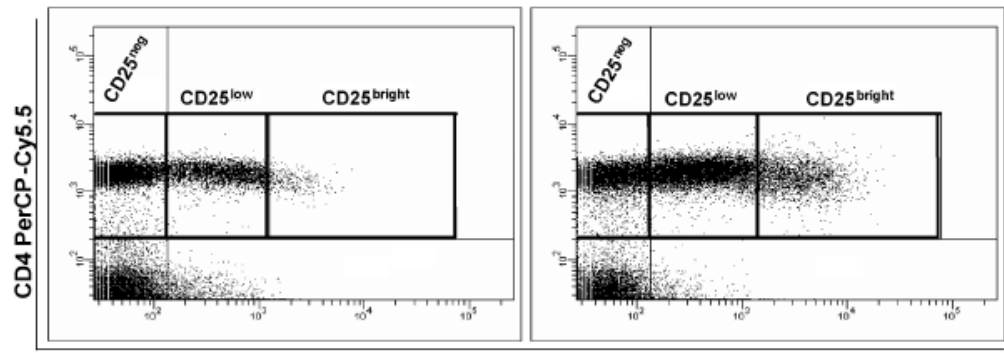

CD25-PE

D

PB

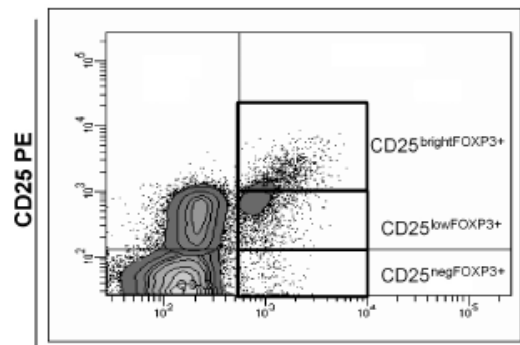

SF

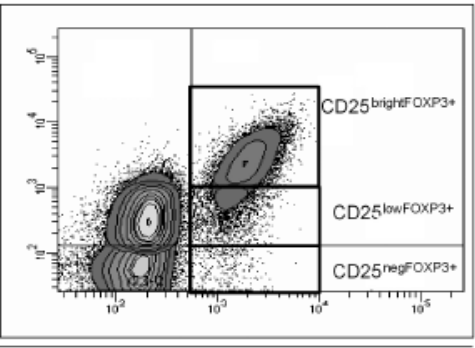

FOXP3 FITC

Figure 1. CD4+CD25+FOXP3+ T cells are increased in synovial fluid (SF) of patients with juvenile idiopathic arthritis (JIA). A. Percentages of CD4+CD25+FOXP3+ T cells in peripheral blood (PB) in 49 healthy controls and 45 patients with JIA. Data are shown as box plots: horizontal lines in the boxes denote 25th, 50th (median), and 75th percentiles; lines outside boxes represent minimum and the maximum value (excluding outliers). B. Percentages of $\mathrm{CD} 4+\mathrm{CD} 25+\mathrm{FOXP} 3+\mathrm{T}$ cells in $\mathrm{PB}$ and SF from patients with JIA. Paired samples of PB and $\mathrm{SF}$ were obtained from 20 patients with JIA. Each line represents values from individual patients. C. Representative dot plot for CD4 and CD25 staining in a paired PB (left panel) and SF (right panel) clinical sample. Quadrants are based on unstained control cells. Gates used for definition of CD4+CD25+T cell subpopulations with negative (CD25-), intermediate (low), and high CD25 expression (bright) are indicated. D. Three-color FACS contour plots showing comparative analysis of FOXP3 expression within the different CD4+ T cell subsets, as indicated in panel C. Analysis was performed on CD4 gated T cells. Quadrants for FOXP3 were based on the isotype negative control antibody. Data are representative of $20 \mathrm{~PB}$ and SF paired samples.

0.78; $\mathrm{p}=0.001)$. As expected, FOXP3 was uniformly more expressed (>90\%) in CD25bright $\mathrm{T}$ cells in both $\mathrm{PB}$ and $\mathrm{SF}$ compartments. Moreover, in the inflamed joint we observed a statistically significant increase in FOXP3 expression also in $\mathrm{CD} 4+\mathrm{CD} 25$ low $\mathrm{T}$ cells (median $\pm \mathrm{SD}, 35 \pm 18.5 \%$ vs 24 $\pm 11.3 \%, \mathrm{p}<0.001)$ and, albeit to a lesser extent, in the CD4+CD25- T cell subpopulation $(8.3 \pm 6.6 \%$ vs $1.5 \pm$ $1.1 \%, \mathrm{p}<0.001$ ) when compared to the periphery.

To determine whether the high percentage of $\mathrm{CD} 4+\mathrm{FOXP3}+$ in SF was associated with an increased level 
of FOXP3 density per cell, we also examined the differences in FOXP3 MFI, which reflects the amount of FOXP3 protein per cell. No difference in the FOXP3 fluorescence intensity was observed in PB between patients and control subjects. Importantly, we found a significantly higher MFI of FOXP3 in $\mathrm{CD} 4+\mathrm{FOXP3}+\mathrm{SF}$ T cells compared to their PB counterparts (median \pm SD, arbitrary units, $54 \pm 22.6$, range $17.1-90$ vs $19.5 \pm 4.2$, range $15-30 ; \mathrm{p}<0.001$ ). Together, these data suggest that FOXP $3 \mathrm{~T}$ cells could be selectively recruited from a circulating pool into the JIA inflamed synovium. Moreover, the higher levels of SF
FOXP3 MFI suggest that an upregulation of FOXP3 expression per cell also occurs in the inflammatory joint.

Reciprocal relationship between RORC2 and FOXP3 transcript levels in inflamed joints. Significantly lower FOXP3 mRNA transcript levels were seen in patient $\mathrm{PB}$ versus control $\mathrm{PB}$, irrespective of disease type (median, 0.7-fold, $\mathrm{p}<$ 0.001, Figure 2A). As expected, FOXP3 mRNA levels strongly correlated with percentages of $\mathrm{CD} 4+\mathrm{FOXP} 3+$ and CD4+CD25+FOXP3+ T cells $(r=0.666 \mathrm{p}<0.001$ and $\mathrm{r}=$ $0.630 \mathrm{p}<0.001$, respectively; data not shown). A higher presence of Treg cells in SF was confirmed by real-time

\section{A}

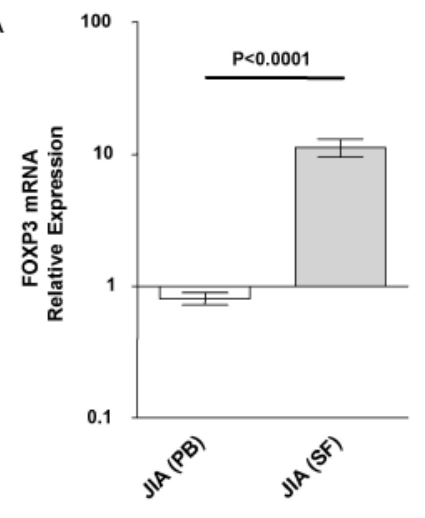

B

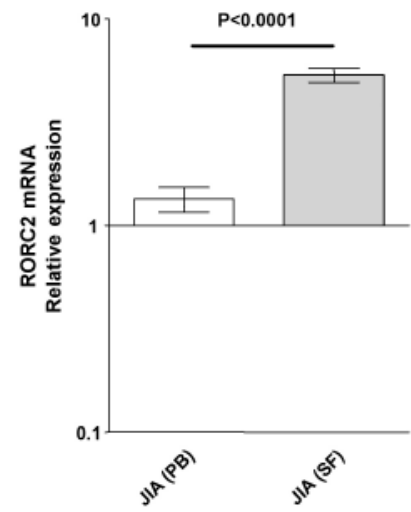

C

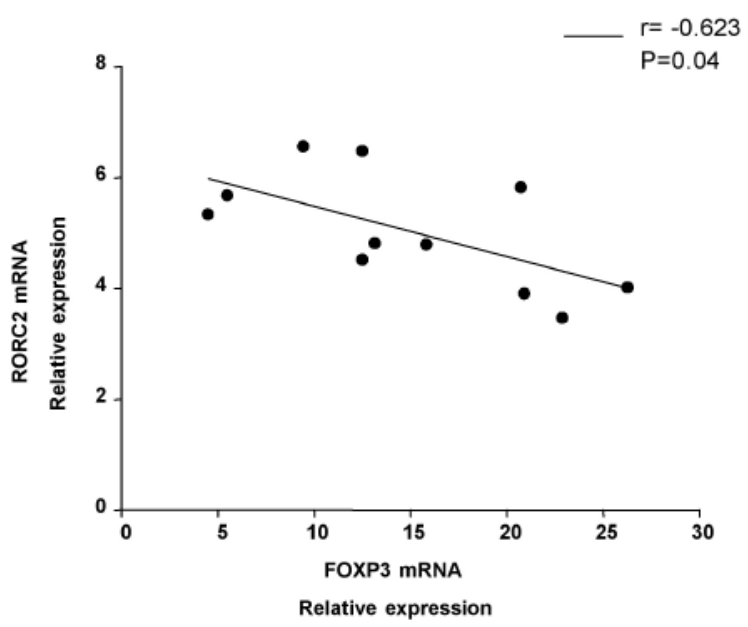

Figure 2. FOXP3 exhibits a reciprocal relationship with RORC2 at the site of inflammation. A. FOXP3 mRNA expression in JIA patients and healthy controls. Real Time PCR of FOXP3 mRNA expression in PBMC of 58 JIA patients (left bar) and in SFMC of 20 JIA patients (right bar). Results are relative to pooled cDNA from age and sex matched healthy controls $(n=45$, represented by $x$ axis $=1$ ). FOXP3 expression levels are calculated by the $2^{-\Delta 4} \mathrm{CT}$ fold method. Each experiment was standardized using RNaseP as an endogenous reference gene. B. RORC2 mRNA expression in JIA patients and healthy controls. Real Time PCR of RORC2 mRNA expression in PBMC of 11 JIA patients (left bar) and in SFMC of 11 JIA patients (right bar). Results are relative to pooled cDNA from age and sex matched healthy controls $(\mathrm{n}=15$, represented by $\mathrm{x}$ axis $=$ 1). RORC2 expression levels were determined with the $2^{-\Delta 4} \mathrm{CT}$ fold method and presented as fold change. Each experiment was standardized using RNaseP as an endogenous reference gene. C. Reciprocal relationship between RORC2 and FOXP3 transcript levels in inflamed joints of children with JIA $(\mathrm{n}=11)$. 
RT-PCR for FOXP3 mRNA, since the FOXP3 transcript levels were significantly higher in SFMC than in paired PBMC (median fold increase: 13.6, $\mathrm{p}<0.0001$ ).

Patients with JIA also displayed significantly higher expression of Th17 master gene regulator RORC2 in SF (median fold increase: 3.9, $\mathrm{p}<0.0001$; see Figure 2B) than in paired $\mathrm{PB}$ samples, but notably there was an inverse significant correlation between FOXP3 and RORC2 transcript levels $(\mathrm{r}=-0.623, \mathrm{p}=0.04$, Figure $2 \mathrm{C})$.

Cytokine production by PBMC and SFMC in JIA. No detectable levels of spontaneously produced IL-17 were detected in unstimulated PBMC and SFMC; therefore, activation of PBMC was performed with PMA/ionomycin, which induced the highest cytokine responses in terms of IL-17 secretion. The optimal time condition for IL-17 detection was established after 48 hours (data not shown).

As for paired PBMC/SFMC samples, stimulated SFMC displayed an impaired ability to produce IL-17 when compared with PBMC (median value \pm SD: $100 \mathrm{pg} / \mathrm{ml} \pm 28.2$ $\mathrm{pg} / \mathrm{ml}$ vs $225.5 \mathrm{pg} / \mathrm{ml} \pm 101.6 \mathrm{pg} / \mathrm{ml} ; \mathrm{p}=0.0067)$. As expected, a lower responsiveness in terms of IL-6 secretion was also observed in activated SFMC when compared with their PB counterpart $(31.5 \pm 19.9$ vs $112.5 \pm 46.8 ; \mathrm{p}=0.00062)$. In contrast, stimulated SFMC were significantly able to release higher amounts of the antiinflammatory cytokine IL-10 (about 6.4-fold increase, $\mathrm{p}=0.00036$ ). Interestingly, we found an inverse relationship between IL-17 levels and percentage of CD4+CD25+FOXP3+ SF T cells $(r=-0.510$, $\mathrm{p}=0.047$ ). With regards to the other cytokines (IL-2, IL-4, IFN- $\gamma$, TNF- $\alpha$ ), we found that their concentrations were higher in SFMC than in their PB counterparts (data not shown).

\section{DISCUSSION}

Our study confirms at transcriptional level that a negative feedback system between Th17 and Treg cells occurs within the joints of patients with JIA. In agreement with this hypothesis, we found that FOXP3 and RORC 2 transcription factors coexist in the inflammatory joint environment, where they appear to be reciprocally correlated. This finding is of particular interest for several reasons. First, it confirms and extends the hypothesis that a Th17 enrichment occurs in inflamed joints as has been recently reported by Nistala, et $a l^{38}$, reinforcing the concept of a new potential pathogenic role of these cells in JIA. So, although JIA is traditionally accepted as an autoimmune disease with a predominant Th1 response pattern, our results and those of Nistala, et al suggest that also Th17 and Treg cells may have an important role in its pathogenesis. Our study demonstrates, for the first time, molecular evidence for a reciprocal relationship between RORC2 and FOXP3 transcript levels in SF. Of note, since there was no commercial probe available for the Th17 master transcription factor RORC2, we used custom-designed RORC2 primers and probe, while other stud- ies have used a probe that detects both variants of RORC, deriving RORC2 expression only in an indirect way ${ }^{42}$. This is of interest, given the different patterns of expression of the 2 isoforms, as initially demonstrated in mice by $\mathrm{He}$, et $a l^{32}$. The finding of increased RORC2 expression in SF might partly explain the impaired resistance to apoptosis seen in SF lymphocytes of JIA patients ${ }^{43,44}$ since ROR $\gamma t$, the equivalent of RORC2 in mice, was shown to protect T cells from activation-induced cell death ${ }^{32}$. An antagonistic immune response between Treg and Th17 in situ in the joints of patients with JIA is in line with recent findings showing that Treg and Th17 cells are reciprocally regulated during differentiation ${ }^{34}$. In further support of this hypothesis it is worth noting that 2 independent groups have recently reported that induction of FOXP3 could be a mechanism for suppression of Th17 differentiation ${ }^{45,46}$. In fact, Ichiyama, et al reported that FOXP3 directly interacted with ROR $\gamma t$ through exon 2 region and suppressed ROR $\gamma$ t-mediated IL-17A promoter activation. In addition, Du, et al showed that the full-length FOXP3 isoform (but not the alternative-spliced product lacking the exon 2) interacts with ROR $\alpha$ (another related nuclear receptor recently implicated in Th17 lineage-specification ${ }^{47}$ ) inhibiting Th17 differentiation by antagonizing its transcriptional activity. We also show a decreased percentage of both CD4+FOXP3+ and CD4+CD25+FOXP3+ in JIA patient PB compared to healthy controls, and a significantly increased percentage in SF. These results corroborate and extend earlier observations from other authors ${ }^{38,48-50}$, indicating that the outcome of JIA may in part be a matter of immune regulation (for review, see ${ }^{51}$ ). Contrary to what has been shown by others $^{38,49,52}$, we failed to detect any statistically significant differences between subgroups of JIA patients studied, either as abundant CD4+CD25+FOXP3+ and CD4+FOXP3+ $\mathrm{T}$ cells or abundant FOXP3 mRNA transcripts. However, it is difficult to compare our data with those reported because of different experimental settings. In this regard, it should be noted that a significant difference between the subgroups of JIA patients was first reported only in exploring the frequency of CD4 T cells expressing CD25 at various levels ${ }^{49}$, and only very recently has this difference been confirmed examining FOXP3 expression ${ }^{38}$. Moreover, another possible explanation of these differences might be related to clinical and pharmacological heterogeneity within patient groups.

We were also able to show that, in the inflamed joint, an increased percentage of FOXP3-expressing cells was also evident in CD4+CD25low $\mathrm{T}$ cells and, albeit to a lesser extent, in the $\mathrm{CD} 4+\mathrm{CD} 25-\mathrm{T}$ cell subpopulations. Interestingly, higher FOXP3 MFI in SFMC was observed, suggesting that cytokine microenvironments could act locally to upregulate FOXP3 expression per cell. This is of interest, since it has been shown that additional populations of regulatory cells (namely, adaptive Treg cells) with a variable 
level of expression of CD25 can be generated in the periphery (induced Tregs) after exposure to antigen in a distinct immunological context ${ }^{53}$; moreover as recently reported, the beneficial effect of autologous stem cell transplantation in juvenile idiopathic arthritis (JIA) is due either to restoration of the frequency of FOXP3 expressing CD4+CD25bright regulatory $\mathrm{T}$ cells or to the switch from a proinflammatory to a tolerant phenotype ${ }^{54}$. Our results also provide phenotypic findings that emphasize the importance of CD4+ T cells expressing intermediate levels of CD25 in maintaining a local tolerogenic response, as already suggested in a more detailed functional analysis by de Kleer, et $a l^{49}$ and Ruprecht, et $a l^{50}$. The latter study showed that the CD4+CD25+ population in JIA SF comprises both regulatory and effector $\mathrm{T}$ cells that can be distinguished by CD27 expression, and that those cells co-expressing $\mathrm{CD} 4+\mathrm{CD} 25+\mathrm{CD} 27+$ are characterized by higher amounts of FOXP3 mRNA and are more suppressive on $\mathrm{T}$ cell proliferation when compared with CD4+CD25+CD27- cells. Indeed, our results show that SFMC produce more FOXP3 proteins per cell than PBMC.

Since it has been postulated that antigen-stimulated cells differentiate into either Th17 or Treg cells depending on the cytokine-regulated balance of ROR $\gamma t$ and $\mathrm{FOXP}^{55}$, we studied the functional characteristics of PBMC and SFMC, evaluating their IL-17 and Th1/Th2 cytokine production profiles in cell culture supernatants. Surprisingly, despite the fact that levels of RORC2 mRNA were higher in SFMC than in PBMC, and although synovial cells exhibit a more activated phenotype than PBMC, we found that stimulated SFMC displayed an impaired ability to produce IL-17 when compared with PBMC. This result is consistent with the report by Ziolkowska, et $a l^{20}$, who similarly showed a different response in terms of IL-17 production between PBMC and SFMC in patients with rheumatoid arthritis.

These data, together with the inverse relationship between IL-17 levels and the percentage of CD4+CD25+ FOXP3+ SF T cells, suggest a negative feedback mechanism between FOXP3+ Treg cells and IL-17 (RORC2) secreting cells in JIA. However, we cannot exclude that this phenomenon could be partially due to a functional exhaustion of IL-17 producing cells in SF.

We acknowledge the limitations of our study. We did not perform functional assays, and it is known that the interpretation of phenotypic results based on FOXP3 flow cytometry expression alone must be interpreted with great caution, particularly in patients with autoimmune or infectious disease whose cells are potentially activated. On the other hand, it is worth noting that for the detection of FOXP3 we used 259D anti-FOXP3 monoclonal antibody (Biolegend), that has been shown to give better results with human activated $\mathrm{T}$ cells ${ }^{56}$ when compared with PCH101 monoclonal antibody (eBioscience).

In conclusion, the local enrichment of regulatory T cells, either due to a selective recruitment from a regulatory peripheral pool or due to an induction at the site of inflammation, is consistent with the possibility that regulatory $\mathrm{T}$ cells are actively involved in regulating local inflammatory responses in JIA. Analyses of the factors that influence the reciprocal balance between RORC2 and FOXP3 in situ will clearly help elucidate disease pathogenesis and lead to more specific treatments.

\section{ACKNOWLEDGMENT}

We thank Dr. Lucy Wedderburn for thoughtful discussion about the study and the manuscript.

\section{REFERENCES}

1. Wedderburn LR, Robinson N, Patel A, Varsani H, Woo P. Selective recruitment of polarized T cells expressing CCR5 and CXCR3 to the inflamed joints of children with juvenile idiopathic arthritis. Arthritis Rheum 2000;4:765-74.

2. Romagnani S. Lymphokine production by human $\mathrm{T}$ cells in disease states. Annu Rev Immunol 1994;12:227-57.

3. Dolhain RJ, van der Heiden AN, ter Haar NT, Breedveld FC, Miltenburg AM. Shift toward T lymphocytes with a T helper 1 cytokine-secretion profile in the joints of patients with rheumatoid arthritis. Arthritis Rheum 1996;12:1961-9.

4. Miossec P, van den Berg W. Th1/Th2 cytokine balance in arthritis. Arthritis Rheum 1997;12:2105-15.

5. Harrington LE, Hatton RD, Mangan PR, et al. Interleukin-17-producing CD4+ effector T cells develop via a lineage distinct from the $\mathrm{T}$ helper type 1 and 2 lineages. Nat Immunol 2005;11:1123-32.

6. Park H, Yang XO, Chang SH, et al. A distinct lineage of CD4 T cells regulates tissue inflammation by producing interleukin 17 . Nat Immunol 2005;11:1133-41

7. Hori S, Nomura T, Sakaguchi S. Control of regulatory T cell development by the transcription factor FOXP3. Science 2003;299:1057-61.

8. Steinman L. A brief history of $\mathrm{TH} 17$, the first major revision in the TH1/TH2 hypothesis of T cell-mediated tissue damage. Nat Med 2007; 13:139-45.

9. Bettelli E, Korn T, Oukka M, Kuchroo VK. Induction and effector functions of T(H)17 cells. Nature 2008;453:1051-7.

10. Reiner SL. Development in motion: helper T cells at work. Cell 2007;129:33-36.

11. Afzali B, Lombardi G, Lechler RI, Lord GM. The role of T helper 17 (Th17) and regulatory T cells (Treg) in human organ transplantation and autoimmune disease. Clin Exp Immunol 2007; 148:32-46.

12. Weaver CT, Hatton RD, Mangan PR, Harrington LE. IL-17 family cytokines and the expanding diversity of effector $\mathrm{T}$ cell lineages. Annu Rev Immunol 2007;25:821-52.

13. Ouyang W, Kolls JK, Zheng Y. The biological functions of T helper 17 cell effector cytokines in inflammation. Immunity 2008;28:454-67.

14. Miossec P. Interleukin-17 in rheumatoid arthritis: if T cells were to contribute to inflammation and destruction through synergy. Arthritis Rheum 2003;48:594-601.

15. Aggarwal S, Gurney AL. IL-17: prototype member of an emerging cytokine family. J Leukoc Biol 2002;71:1-8.

16. Lubberts E, Joosten LA, Oppers B, et al. IL-1-independent role of IL-17 in synovial inflammation and joint destruction during collagen-induced arthritis. J Immunol 2001;167:1004-13.

17. Koenders MI, Lubbert E, Oppers-Walgreen B, et al. Induction of cartilage damage by overexpression of $\mathrm{T}$ cell interleukin-17A in 
experimental arthritis in mice deficient in interleukin-1. Arthritis Rheum 2005;52:975-83.

18. Nakae S, Nambu A, Sudo K, Iwakura Y. Suppression of immune induction of collagen induced arthritis in IL-17-deficient mice. J Immunol 2003;171:6173-7.

19. Chabaud M, Durand JM, Buchs N, et al. Human interleukin-17: A $\mathrm{T}$ cell-derived proinflammatory cytokine produced by the rheumatoid synovium. Arthritis Rheum 1999;42:963-70.

20. Ziolkowska M, Koc A, Luszczykiewicz G, et al. High levels of IL-17 in rheumatoid arthritis patients: IL-15 triggers in vitro IL-17 production via cyclosporin A-sensitive mechanism. J Immunol 2000;164:2832-8

21. Kotake S, Udagawa N, Takahashi N, et al. IL-17 in synovial fluids from patients with rheumatoid arthritis is a potent stimulator of osteoclastogenesis. J Clin Invest 1999;103:1345-52.

22. Aggarwal S, Misra R, Aggarwal A. Interleukin 17 levels are increased in juvenile idiopathic arthritis synovial fluid and induce synovial fibroblasts to produce proinflammatory cytokines and matrix metalloproteinases. J Rheumatol 2008;35:515-9.

23. Sakaguchi S, Ono M, Setoguchi R, et al. FOXP3+CD25+CD4+ natural regulatory $\mathrm{T}$ cells in dominant self-tolerance and autoimmune disease. Immunol Rev 2006;212:8-27.

24. Sakaguchi S, Yamaguchi T, Nomura T, Ono M. Regulatory T cells and immune tolerance. Cell 2008;133:775-87.

25. Vignali DA, Collison LW, Workman CJ. How regulatory T cells work. Nat Rev Immunol 2008;8:523-32.

26. Sakaguchi S. Naturally arising CD4+ regulatory T cells for immunologic self-tolerance and negative control of immune responses. Annu Rev Immunol 2004;22:531-62.

27. Horwitz DA, Zheng SG, Gray JD. Natural and TGF-beta-induced FOXP3(+)CD4(+) CD25(+) regulatory T cells are not mirror images of each other. Trends Immunol 2008;29:429-35.

28. Bluestone JA, Abbas AK. Natural versus adaptive regulatory T cells. Nat Rev Immunol 2003;3:253-7.

29. Ivanov II, Mackenzie BS, Zhou L, et al. The orphan nuclear receptor ROR $\gamma t$ directs the differentiation program of proinflammatory IL-17+ T helper cells. Cell 2006;126:1121-31.

30. Fontenot JD, Gavin MA, Rudensky AY. FOXP3 programs the development and function of CD4+CD25+ regulatory T cells. Nat Immunol 2003;4:330-6.

31. Zheng Y, Rudensky AY. Foxp3 in control of the regulatory T cell lineage. Nat Immunol 2007;8:457-62.

32. He YW, Deftos ML, Ojala EW, Bevan MJ. RORgamma t, a novel isoform of an orphan receptor, negatively regulates Fas ligand expression and IL-2 production in T cells. Immunity 1998;9:797-06.

33. Manel N, Unutmaz D, Littman DR. The differentiation of human $\mathrm{T}(\mathrm{H})-17$ cells requires transforming growth factor-beta and induction of the nuclear receptor RORgammat. Nat Immunol 2008;9:641-9

34. Bettelli E, Carrier Y, Gao W, et al. Reciprocal developmental pathways for the generation of pathogenic effector TH17 and regulatory T cells. Nature 2006;441:235-8.

35. Veldhoen M, Hocking RJ, Atkins CJ, Locksley RM, Stockinger B TGF-beta in the context of an inflammatory cytokine milieu supports differentiation of IL-17-producing T cells. Immunity 2006;24:179-89.

36. Mangan PR, Harrington LE, O'Quinn DB, et al. Transforming growth factor beta induces development of the $\mathrm{T}(\mathrm{H}) 17$ lineage. Nature 2006;441:231-4.

37. O'Garra A, Stockinger B, Veldhoen M. Differentiation of human T(H)-17 cells does require TGF-beta! Nat Immunol 2008;9:588-90.

38. Nistala K, Moncrieffe H, Newton KR, Varsani H, Hunter P, Wedderburn LR. Interleukin-17-producing $\mathrm{T}$ cells are enriched in the joints of children with arthritis, but have a reciprocal relationship to regulatory T cell numbers. Arthritis Rheum 2008;58:875-87.

39. Petty RE, Southwood TR, Manners P, et al. International League of Associations for Rheumatology classification of juvenile idiopathic arthritis: second revision, Edmonton, 2001. J Rheumatol 2004;31:390-2.

40. Baecher-Allan C, Brown JA, Freeman GJ, Hafler DA. CD4+CD25high regulatory cells in human peripheral blood. J Immunol 2001;167:1245-53

41. Livak K, Schmittgen TD. Analysis of relative gene expression data using real-time quantitative PCR and the 2(-Delta Delta $\mathrm{C}(\mathrm{T})$ ) Method. Methods 2001;25:402-8.

42. Koenen HJ, Smeets RL, Vink PM, van Rijssen E, Boots AM, Joosten I. Human CD25highFoxp3pos regulatory T cells differentiate into IL-17-producing cells. Blood 2008;112:2340-52.

43. Smolewska E, Cebula B, Brozik H, Stanczyk J. Relationship between impaired apoptosis of lymphocytes and distribution of dendritic cells in peripheral blood and synovial fluid of children with juvenile idiopathic arthritis. Arch Immunol Ther Exp 2008;56:283-9.

44. Smolewska E, Stanczyk J, Robak T, Smolewski P. Inhibited apoptosis of synovial fluid lymphocytes in children with juvenile idiopathic arthritis is associated with increased expression of myeloid cell leukemia 1 and XIAP proteins. J Rheumatol 2006;33:1684-90

45. Ichiyama K, Yoshida H, Wakabayashi Y, et al. Foxp3 inhibits RORgammat-mediated IL-17A mRNA transcription through direct interaction with RORgammat. J Biol Chem 2008;283:17003-8.

46. Du J, Huang C, Zhou B, Ziegler SF. Isoform-specific inhibition of ROR alpha-mediated transcriptional activation by human FOXP3 J Immunol 2008;180:4785-92.

47. Yang XO, Pappu BP, Nurieva R, et al. T helper 17 lineage differentiation is programmed by orphan nuclear receptors ROR alpha and ROR gamma. Immunity 2008;28:29-39.

48. de Kleer IM, Kamphuis SM, Rijkers GT, et al. The spontaneous remission of juvenile idiopathic arthritis is characterized by CD30+ $\mathrm{T}$ cells directed to human heat-shock protein 60 capable of producing the regulatory cytokine interleukin-10. Arthritis Rheum 2003;48:2001-10

49. de Kleer IM, Wedderburn LR, Taams LS, et al. CD4+CD25bright regulatory $\mathrm{T}$ cells actively regulate inflammation in the joints of patients with the remitting form of juvenile idiopathic arthritis J Immunol 2004;172:6435-43.

50. Ruprecht CR, Gattorno M, Ferlito F, Gregorio A, Martini A, Lanzavecchia A. Coexpression of CD25 and CD27 identifies FoxP3+ regulatory $\mathrm{T}$ cells in inflamed synovia. J Exp Med 2005;201:1793-3

51. de Kleer IM, Albani S, Prakken BJ. T-cell regulation in juvenile idiopathic arthritis. Future Rheumatol 2006;1:111-9.

52. Lorenzi AR, Morgan TA, Anderson AE, et al. Thymic function in juvenile idiopathic arthritis. Ann Rheum Dis 2009:68:983-90.

53. Zheng SG. The critical role of TGF-beta 1 in the development of induced Foxp3+ regulatory T cells. Int J Clin Exp Med 2008;1:192-202.

54. de Kleer I, Vastert B, Klein M, et al. Autologous stem cell transplantation for autoimmunity induces immunologic self-tolerance by reprogramming autoreactive $\mathrm{T}$ cells and restoring the CD4+CD25+ immune regulatory network. Blood 2006;107:1696-2

55. Zhou L, Lopes JE, Chong MM, et al. TGF-beta-induced Foxp3 inhibits $\mathrm{T}(\mathrm{H}) 17$ cell differentiation by antagonizing RORgammat function. Nature 2008;453:236-40

56. Tran DQ, Ramsey H, Shevach EM. Induction of FOXP3 expression in naive human CD4+FOXP3 T cells by T-cell receptor stimulation is transforming growth factor-beta dependent but does not confer a regulatory phenotype. Blood 2007;110:2983-90. 